Balkan Araştırma Enstitüsü Dergisi / Journal of Balkan Research Institute Cilt/Volume 9, Sayi/Number 1, Temmuz/July 2020, ss. 261-268.

DOI: 10.30903/Balkan.746618

KİTAP DEĞERLENDİRME - BOOK REVIEW

Yasemin Demircan, Levent Kayapınar, Ayşe Kayapınar, Ege Adaları Tarihi: Kikladlar, Türk Tarih Kurumu, Ankara 2020, 2 Cilt, xxi + 787 sayfa, ISBN: 978-975-17-4452-4.

\title{
Orçun NALEZEN*
}

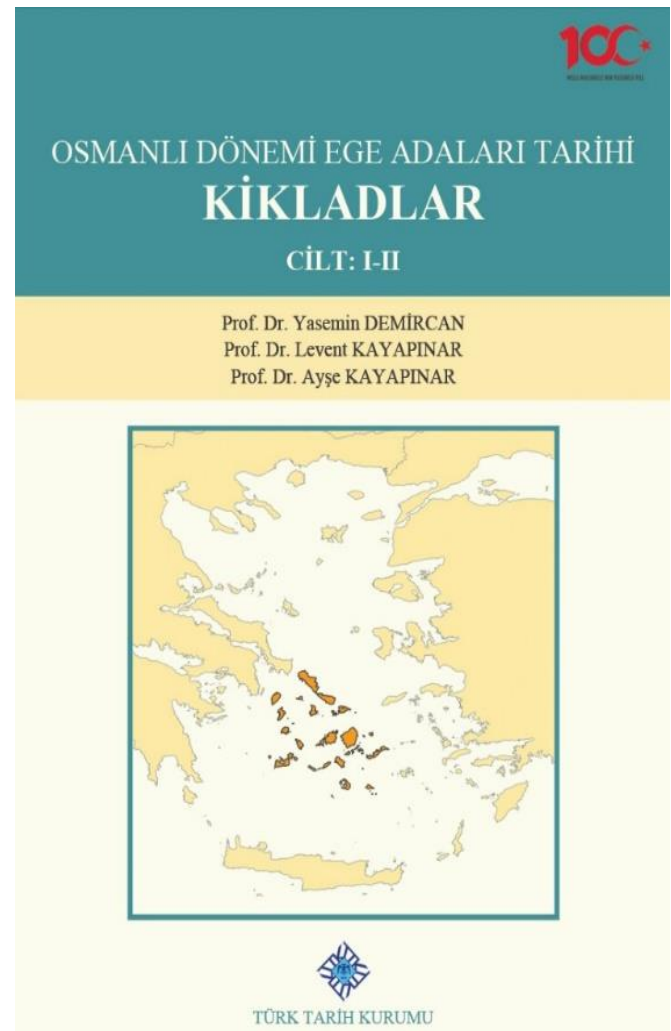

Yunan ana karasının doğusunda, Atina açılarında yer alan Kiklad (Cyclades) Adaları, Osmanlı imparatorluk coğrafyasının belki de hikâyesi en az anlatılmış sahalarından biridir. Oysa bölge, Erken Modern Dönem'de tarihî ve kültürel gelenekler bağlamında aynı anda birden fazla çağın yaşandığ 1 istisnai bir coğrafyadır. Kikladlar, ekmeğini taştan çıkaran Rum köylüleri, İtalyan aristokrasisinden gelmelerine rağmen birer toprak zengininden daha fazlası olmayan Latinleri, farkl1 milletlerden korsanları, rahipleri ve keşişleriyle Akdeniz'i, bilhassa Osmanlı Akdeniz'ini, anlamak isteyen tarihçiler için bir çeşit laboratuvar sayılır. Bu kitapta Yasemin Demircan, Levent Kayapınar ve Ayşe

Kayapınar tarafından büyük bir titizlikle Latin harfli çevirisi yapılan ve

* Arş. Gör., Kastamonu Üniversitesi, Fen Edebiyat Fakültesi Tarih Bölümü, Kastamonu, ORCID: https://orcid.org/0000-0003-1149-3261, E-posta: orcunnalezen@ gmail.com 
değerlendirilen, bölgenin mevcut en eski mufassal tahrir defteri, tüm bu çeşitliliğin meydana getirdiği mozaiği açık bir şekilde yansıtmaktadır. Dolayısıyla söz konusu defterin transkripsiyonu ve değerlendirmesinin yapılmasıyla Osmanlı hâkimiyeti altında Kiklad Adalarındaki toplumsal ve ekonomik dinamikleri yansıtan somut verileri aktarma ve bu verileri anlaşı1ır k1lma amacının güdüldüğü görülmektedir.

Eserin II. cildinde çevirisine yer verilen 800 numaralı tahrir defteri 1669/1670 yılı sayımına ait kayıtları içermektedir. Tahrir, Girit Seferleri sonrasında Ege'deki Osmanlı egemenliği altındaki topraklara yeni bir nizam vermek gibi kapsamlı bir hedef doğrultusunda meydana getirilmiştir. Dolayısıyla yazarların kolektif bir şekilde Latin harfli çevirisini sundukları defter, Kikladlar'daki yeni bir dönemin başlangıcında, yani bir çeşit dönüm noktasında, yaşanmakta olan durumu yansıtmaktadır. Eserde sunulan değerlendirmeler, tahririn hem bölgeye has koşulları korumaya dönük olarak hukuki güvence sağladığını hem de adaları imparatorluk genelinde cari olan idari ve mali yapının bir parçası hâline getirdiğini göstermektedir. Bu bakımdan 800 numaralı mufassal tahrir defteri yalnız Kikladlar için değil, genel anlamda Osmanlı Ege'si için önemli bir kaynaktır.

Geçmişe sosyal ve ekonomik veçhelerden bakmaya dayanan tarihçilik pratiği, modern Osmanlı tarih yazımında güçlü bir şekilde kök salmıştır. Tahrir defterlerinin tarihî ehemmiyeti de bu bağlamda isabetli bir şekilde takdir edilegelmiştir. Kitapta, Latin harfli çevirisine yer verilen 800 numaralı tahrir defterinin sunduğu ipuçları takip edilerek başta Nakşa (Naxos) Adası olmak üzere Para (Paros), Santorin (Santorini), Değirmenlik (Milo), Andra (Andros) ve Şira (Syra) adalarının ekonomik kapasitesi, yerleşim tipolojisi, nüfusu, üretim ilişkileri ve dinî kurumlarına ilişkin kapsamlı değerlendirmeler yapıldığ 1 görülmektedir. Her ne kadar tahrir defterleri incelikli bir araştırma için muazzam boyutlarda veri sunma kapasitesine sahip olsa da tahrirlerin ait olduğu sahada üretilmiş belge serileri olmadan bu verileri işlemek oldukça güçtür. Kikladlar'a ait mahkeme kayıtları yani toplumsal yaşamı belgeleyen en zengin kaynaklardan olan şeriye sicilleri ne yazık ki mevcut değildir. Bu sebeple Kikladlar'daki toplumsal yaşamı anlayabilmek ve anlatabilmek için yazarların başka kaynaklara yöneldiği görülür.

Levant'n egzotik cazibesi Orta Çăg'ın sonlarından itibaren seyyahları Osmanlı ülkesine çekti. Birçoğunun deniz yolculuğunu seçmesi Kiklad Adaları hakkında canlı tasvirlerin günümüze kadar ulaşmasını sağladı 
(s. 170). Seyyahların bu küçük adalar hakkında bilgi vermekte bu kadar cömert davranmasının sebebi buna mecbur olmalarından kaynaklanıyordu. Doğrudan Kudüs'e ya da Misır'a gitmiyorlarsa Yunan ana karasının doğusundan itibaren kuzeye doğru Kikladlar'ın arasından geçmeleri gerekiyordu. Hâkim rüzgârlar ve akıntılar, denizcileri bu adaların arasına sürüklüyordu. ${ }^{1}$ Adaların bu gönüllü ya da zorunlu ziyaretçilerinin gezi notlarından, tahrir verilerinin işlenmesinde yararlanıldığı görülmektedir. Böylece mekanik kayıtlar, okuyucunun karşısına canlı bir tarihsel anlatının parçası olarak sunulabilmiştir.

Eserin kolektif bir şekilde kaleme alınan "Giriş” bölümü, okuyucu için bir kılavuz niteliğindedir. Bu kısmın başında etimolojik bir yaklaşımla Kikladların Ege'deki konumu ve tarihsel derinlik içindeki yeri, Osmanlar tarafından fethi ele alınmaktadır. Adaların ortak yönleri genel bir yaklaşımla toplumsal çeşitlilik ve iskân durumu bağlamında ortaya konulmaktadır (s. 15). 800 numaralı mufassal tahrir defterinin fiziksel özellikleri aktarıldıktan sonra defterdeki kayıt usulüne ilişkin teknik izahata girişildiği görülür (s. 67). Defter çevirisinde takip edilen usulün açıklandığı kısımda, Adalıların ağzından tahrir heyetinin kulağına, ardından da kâtibin eline ulaşana kadar Yunanca kişi ve yer adlarının geçirdiği değişimin nasıl gözetildiği ifade edilmektedir (s. 8-9). Kikladlar'da kökeni Osmanlı egemenliğinden yüzyıllar öncesine uzanan kültürel uygulamaların ekonomik hayatta meydana getirdiği kavramsal çeşitlilik de bu kısımda ele alınmaktadır. Bu bölümde, yalnız adalardaki vergi uygulamalarında referans alınan ağırlık ve hacim ölçülerini tanımlamamış, buna ek olarak aynı isimle anılsa bile bazı ölçü birimlerinin farklı adalarda farklı hacme/ağırlığa karşılık geldiğini de tespit edilmiştir (s. 10-15). Buradaki teknik açıklamaların okuyucu için değeri, 800 numaralı mufassal tahrir defterinin bir kanunnamesinin bulunmadığ $\breve{1}$ gerçeği dikkate alındığında daha iyi anlaşılacaktır.

XIII. yüzyıldan itibaren idari bir merkez olan Nakşa Adası'na ilişkin değerlendirmeler (s. 17-76), Kikladlar'daki Türk hâkimiyetinin kök saldığ1 XVI. yüzyılın ilk yarısı ile XVII. yüzyılın ikinci yarısı arasındaki uyum ve adaptasyon devresini gözler önüne sermektedir. Yasemin Demircan tarihî, kültürel, toplumsal ve coğrafi hususiyetlerle Osmanlı egemenliğinin tesisi arasında băg kurmaktadır. Bu yaklaşımda stratejik gerekçeler, adaların ekonomik kapasitesi, ulaşımın yalnızca yılın belli dönemlerinde sağlıklı bir

\footnotetext{
${ }^{1}$ John H. Pryor, Geographi, Technology, and War: Studies in the Maritime History of the Mediterranean, 649-1571, Cambridge University Press, Cambridge 1992, s. 94-95.
} 
şekilde gerçekleştirilebilmesi gibi etmenler ön plana çıkarılmakta ve adalarda yürütülen adaptasyon sürecinin bölgenin gerçeklerine uygun bir şekilde işlediği gözler önüne serilmektedir (s. 24-30). Ada'nın fethiyle tahririnin gerçekleştirildiği döneme kadar olan tarihsel boşluk, mühimme hükümleriyle doldurulmuş ve Devlet'in bu adalara ilişkin stratejisi daha geniş bir çerçevede ele alınmıştır. Ortaya çıkan sonuç, bölgedeki Osmanlı egemenliğinin mahiyetini anlamak için kritiktir. Zira modern Yunanistan'ın ulusal kuruluş mitine argüman devşirme gayreti içinde olan geçtiğimiz yüzyılın tarihçileri, Osmanlı Devleti tarafından takip edilen uyum politikasını tarihî gerçeklerinden kopararak ele almışlardır. Apostolos Vakalapoulos'un The Greek Nation'1 bu hususta örnek olarak gösterilebilir. Bu yönüyle Nakşa Adası'na ait değerlendirmeler tarihî anlatı ile gerçekler arasındaki bağın güçlendirilmesine anlamlı katkılar sağlamaktadır.

Venedik Cumhuriyeti'ni bir çeşit imparatorluğa dönüştüren IV. Haçlı Seferi'nin bölgeye İtalyan aristokrasisine mensup çok sayıda maceraperesti çektiği bilinmektedir. Nakşa'ya ilişkin değerlendirmelerde toplumsal yapının unsurlarından biri olarak bu grupların da yerini aldığ 1 görülür. Bu kapsamda XIII. yüzyılın başında yeniden kurgulanan üretim ilişkilerinin ekonomik olduğu kadar toplumsal yansımaları da ele alınmaktadır. Ayrıca Ada'nın iskânında ve Nakşa kasabasının fiziksel görünümünde bu toplumsal yapının ne gibi etkiler uyandırdığı da ifade edilmektedir. Ada'daki Ortodoks Rumlar ile Katolik Latinler arasındaki gerilimlerin belgelere yansıyan yönlerine ilişkin Türkçe literatürdeki yegâne çalışmanın sahibi olan Yasemin Demircan' $1 n^{2}$, değerlendirmelerinde 800 numaralı mufassal tahrir defterinin ötesine uzanan bir veri havuzundan yararlandığı anlaşılmaktadır. Eser, Latinlerle Rumlar arasındaki üretim ilişkilerinin Osmanlı idaresi altında kazandığı hukuki statü ile genel olarak Osmanlı Devleti tarafindan bu iki grup arasındaki ilişkilerin seyrine yönelik müdahalelerin etkilerini anlamak isteyen okuyuculara zengin bir tarihî anlatı sunmaktadır (s. 30-46, 50-56).

"II. Bölüm"de ele alınan Para Adası (s. 79-107) da Yasemin Demircan tarafindan kaleme alınmıştır. Yazar bu bölümde de Nakşa'ya ait değerlendirme sırasındaki yaklaşımını sürdürmüş, Para'yı bir Ege adası olarak ele alırken kendine has özelliklerini de öne çıkarmıştır. Demircan'ın, Ada'nın verilerini değerlendirirken yalnız defterde varlığına işaret edilen ürünlerin değil, kaydedilmemiş ürünlerin de peşinden giderek problem

2 “1720 Tarihli Tahrîr Defterine Göre Nakşa Adası'nda Yapılan Düzenlemeler ve Reâyânın Durumu”, Belleten, C. LXXIII, S. 268, ss. 671-681. 


\section{KITTAP DEĞERLENDİRME}

çözücü bir tutum belirlediği görülmektedir. İklimi ya da faunası komşu adalardan farklı olmayan Para'da zeytin ağaçlarının neden vergilendirilmediği sorusuna getirilen açıklamaları bu kapsamda ele almak mümkündür (s. 98-99). Yazar, tahrir verilerini sistematik bir şekilde açıklayabilmek ve anlaşılır kılmak için tüm tarımsal faaliyetleri, sayısal verilerle iskân merkezi bazında tablo ve grafiklerle sunarken Para'nın yüzyıllardır tarlalarını süren, hayvanlarını otlatan köklü Rum ve Latin ailelerin isimlerini de zikretmiştir. Yazar, değerlendirmelerinde metroloji konusundaki açıklamalarıyla tahrir verileri karşısında okuyucunun yolunu kaybetmesine engel olmuştur. Tarihçi, Nakşa'da olduğu gibi Para'ya ilişkin değerlendirmelerinde de Ada'nın tarımsal üretimine anlamlı sayılabilecek katkılar sağlayan dinî kurumlarını (manastır ve kiliseler) listelemiştir. Özellikle manastır mülklerini işleyen ve yöneten din adamlarının kimliklerine ve manastır düzenindeki yerlerine ilişkin açıklamalarda bulunmuştur (s. 9195).

Santorin Adası'nın değerlendirmesi (s. 109-146) Levent Kayapınar tarafından yapılmıştır. Bu bölümde tahrir verileri ile tarihî gelişmelerin ortaya çıkardığı iktisadi ve toplumsal sonuçlar arasında somut bağlar kurulmakta, Ada'ya özgü koşulların iskândan vergi tarhına kadar olan geniş bir yelpazedeki etkileri gözler önüne serilmektedir. Santorin'in tarihsel realitesine ilişkin kurgulanan denklemde, Ada'nın volkanik aktiviteye sahne olmasının da bir değişken olarak yerini alması, bu kabilden bir yaklaşımın ürünü olarak gösterilebilir (s. 111). Levent Kayapınar, Ada'nın pastoral manzarasının muhtelif yerlerinde beliren tahkimatları gözden kaçırmamış ve bunların sivil maksatlı olduklarını tespit etmiştir (s. 111-112). Bu husus, tarihçinin adayı merkeze alan bakış açısına ilişkin birtakım ipuçları sunmaktadır: Öyle anlaşılıyor ki bu savunma yapılarını Ege'deki mimari gelenek içinde ele almış, fonksiyonlarını göz ardı etmemiş, askerî değil, sosyoekonomik veçheden kavramıştır. Eserin bu bölümünde IV. Haçlı Seferi'nden sonra ortaya çıkan toplumsal görünüme ilişkin izler, Ada'daki iskân merkezlerinin kayıt altına alınma biçiminden hareketle takip edilmiştir (s. 133 vd.).

Kitapta Değirmenlik Adası da Levent Kayapınar tarafından değerlendirilmiştir (s. 147-168). Tarihçi başlangıç olarak Değirmenlik'in, ayırt edici yönlerini tarihî derinlikte aramakta ve sahip olduğu doğal kaynaklara ilişkin muasır tanıklara başvurmaktadır (s. 146-149). Söz konusu bölümde Osmanlı fethi ve takip eden süreç, Ada'daki Latin varlığının dâhil edildiği bir akış içinde ele alınmaktadır (s. 150-155). Ada'nın idari, iktisadi 
ve demografik yapısı içinde vergi mükelleflerini tahrir defterinde kategorize edildiği hâliyle inceleyen yazarın, halkın hukuki statüsünü değerlendirmeler sırasında dikkate aldığı anlaşılmaktadır. Böylece Ada'nın topraklarını işleyen ve ona sahip olanların veyahut Ada'da katma değer üretenlerin kimlikleri somut bir şekilde aktarılabilmiştir. (s. 157 vd.) Yazarın değerlendirmelerine eşlik eden hesaplamalarında yerel ölçü birimlerinin metrik sistemdeki karşı1ıkları gösterilmiş, açıklamalar daha anlaşı1ır hâle getirilmiştir. Kikladlar'ın hemen her adasında olduğu gibi Santorin ve Değirmenlik'te de Katolik manastırlarının yanı sıra Tur-1 Sina, Ayneros ve Patmos gibi Ortodoks inancın önemli merkezlerinde faaliyet gösteren manastırlara ait mülkler bulunuyordu. Levent Kayapınar bu mülklerden tahsil edilen vergileri ele alırken Ada'daki kilise örgütü ve bu örgütü idare eden din adamlarının konumunu aktarmıştır. (s. 166-167).

Eserde Andra Adası'na ilişkin değerlendirmeler (s. 169-198) Ayşe Kayapınar'a aittir. Kitabın bu bölümünde öncelikle Ada'nın tarihçesi ele alınmıştır. Özellikle Osmanlı fethinden öncesine ait gelişmeler tanıkların gözünden sunulmuş, Latin egemenliği döneminde meydana gelen çatışmalar canlı bir şekilde dile getirilmiştir (s. 169-172). Ada'daki Türk idaresi, ekonomik faaliyetler ve iskân hakkındaki değerlendirmelere de aynı yaklaşımın yön verdiği görülmektedir. Tarihçi, açıklamalarını yalnız tahrir defterinden ulaştığı bulgulara dayandırmamış, tespitlerini seyahatnamelerden elde edilen bilgilerle anlaşılır hâle getirmiştir (s. 174 - 177). Ada'nın gelirlerindeki tarihî değişimi ortaya koyabilmek için maliye bürokrasisi tarafından üretilmiş farklı defter serilerinden de yararlanmıştır. Değerlendirmeler kapsamında Adalıların kimliğine ilişkin ayrıntılar paylaşılmakta, Ada'nın toplumsal yapısının XIII. yüzyıl başlarına kadar uzanan bir tarihî seyir içinde tekâmül ettiği gösterilmektedir. Rumlar, Latinler ve dışarıdan gelip üretime katkı sağlayan Müslümanlarla birlikte Ada toplumunun çeşitliliği ortaya konulmaktadır (s. 186-190).

Son olarak Şira Adası'nın da değerlendirmesi (s. 199-212) Ayşe Kayapınar tarafından gerçekleştirilmiştir. Yazar, okuyucuyu tahrir verilerinin işlendiği, ekonomik ve demografik teknik hesaplamaların yer aldığı kısma hazırlamak için XVII. yüzyılda mevcut bulunan koşulları meydana getiren tarihî gelişmeleri ele almıştır. Şira' da Katolik nüfusun nispeten fazla olmasına yönelik getirilen açıklamalar bu hususta örnek olarak gösterilebilir (s. 199202). Tarihçi, Andra'da olduğu gibi Şira'da da adanın zirai ürünlerini ve bu ürünlerin yerel ölçü birimi bazında üretim miktarını, sınai üretim tesislerini ve nüfusunu, tahrir defterinin kurgusu içinde, tablolar hâlinde sunarak 
Ada'nın mali ve demografik durumunu genel bir çerçeve dâhilinde sunmuştur.

Ege Adaları Tarihi: Kikladlar, çok yazarlı olmasına karşın bütüncül ve tutarlı bir yaklaşımın ürünüdür. Üslupta gözlemlenen insicam bu görüşün belki de en önemli dayanaklarından biridir. Eserde konu edinilen adaların her biri için toplam tarımsal alan miktarı, meyveli ağaçların sayısı, istihsali yapılan ürünlerin miktarı, sinai üretim tesislerinden elde edilen gelirlerin tutarı gibi titizlik gerektiren teknik hesaplamaların yapıldığı, bunların tablolar ve grafikler eşliğinde sunulduğu görülür. Ayrıca kaynakçanın ortak olarak belirtilmesine karşıllk her bölümde eser künyelerinin tam olarak verilmesi, okumayı kolaylaştıran etmenlerden biri olarak dikkat çekmektedir. Adaların her birinin değerlendirmesi "Sonuç" başlığı altında sunulan açıklamalarla bitirilmiştir. Buna karşın I. cildin sonunda kolektif bir şekilde kaleme alınan "Sonuç" bahsine yer verilmiştir. Böylece okuyucuya adaların ortak ve farklı yönleri bakımından karşılaştırma yapabilme imkânı sunulduğu anlaşılmaktadır. I. cildin başında yer alan yer adlarının toplu listesi ile transkripsiyonu içeren II. cildin indeksi, tahrir defterinden yararlanmak isteyen araştırmacılar için yol gösterici niteliktedir. $\mathrm{Bu}$, araştırmacıların kolaylıkla herhangi bir iskân merkezindeki sıradan bir köylüye ulaşabilmesine olanak sağlayacak keyfiyettedir. Ek olarak transkripsiyonda takip edilen yöntem, tahrir defterindeki kayıt usulünü yansıtmaktadır.

Ege'nin bir uzak köşesindeki adaların dağlarını ve ovalarını işlemiş olan, büyük çoğunluğu birkaç dönümden daha fazlasına sahip olmayan köylüleri, emeklerinin ve çabalarının en gerçek delili olan vergi kayıtları eşliğinde günümüze taşımak, onların tarihî derinlikteki yerini tayin etmenin belki de en anlamlı yoludur. Bu eserde tarihçiler sadece değerlendirmeleriyle değil, kullandıkları malzemeyi de sunarak hem literatürde ihtiyaç duyulan bir eseri meydana getirmiş hem de bundan sonraki çalışmalar için işlenmeye devam edecek dikkate değer boyuttaki veriyi hizmete sunmuşlardır. Ayşe Kayapınar ve Levent Kayapınar, Rumeli'deki Osmanlı varlığına ilişkin çok sayıda çalışması bulunan ve yalnız Osmanlı arşiv kaynaklarından değil, bölgede konuşulan dillerin bazılarında yazılmış materyallerden de yararlanabilen çok yönlü tarihçilerdir. Yasemin Demircan'ın çalışmalarının neredeyse tamamı Ege Adalarına odaklanır ve birçok açıdan ilk olma özelliği taşır. Demircan, tarihçi Saffet Bey'den ${ }^{3}$ sonra neredeyse 80 yıl boyunca esaslı

\footnotetext{
${ }^{3}$ Safvet, "Nakşa (Naksos) Dukalığı, Kiklad Adaları", TOEM, C. IV, S. 23 (Kanûn-1 evvel 1329), ss. 1444-1457.
} 
bir şekilde ele alınmamış olan Kikladlar üzerine ayakları arşiv belgelerine basan ilk kapsamlı çalışmaları gerçekleştirmiştir. Eseri kaleme alan tarihçilerin geçmişte yürüttükleri araştırmalar dikkate alındığında bu kitabın Ege'deki Türk hâkimiyetine ilişkin çalışmalara ve denizcilik tarihine sağlayacağı katkı daha iyi anlaşılacaktır. 